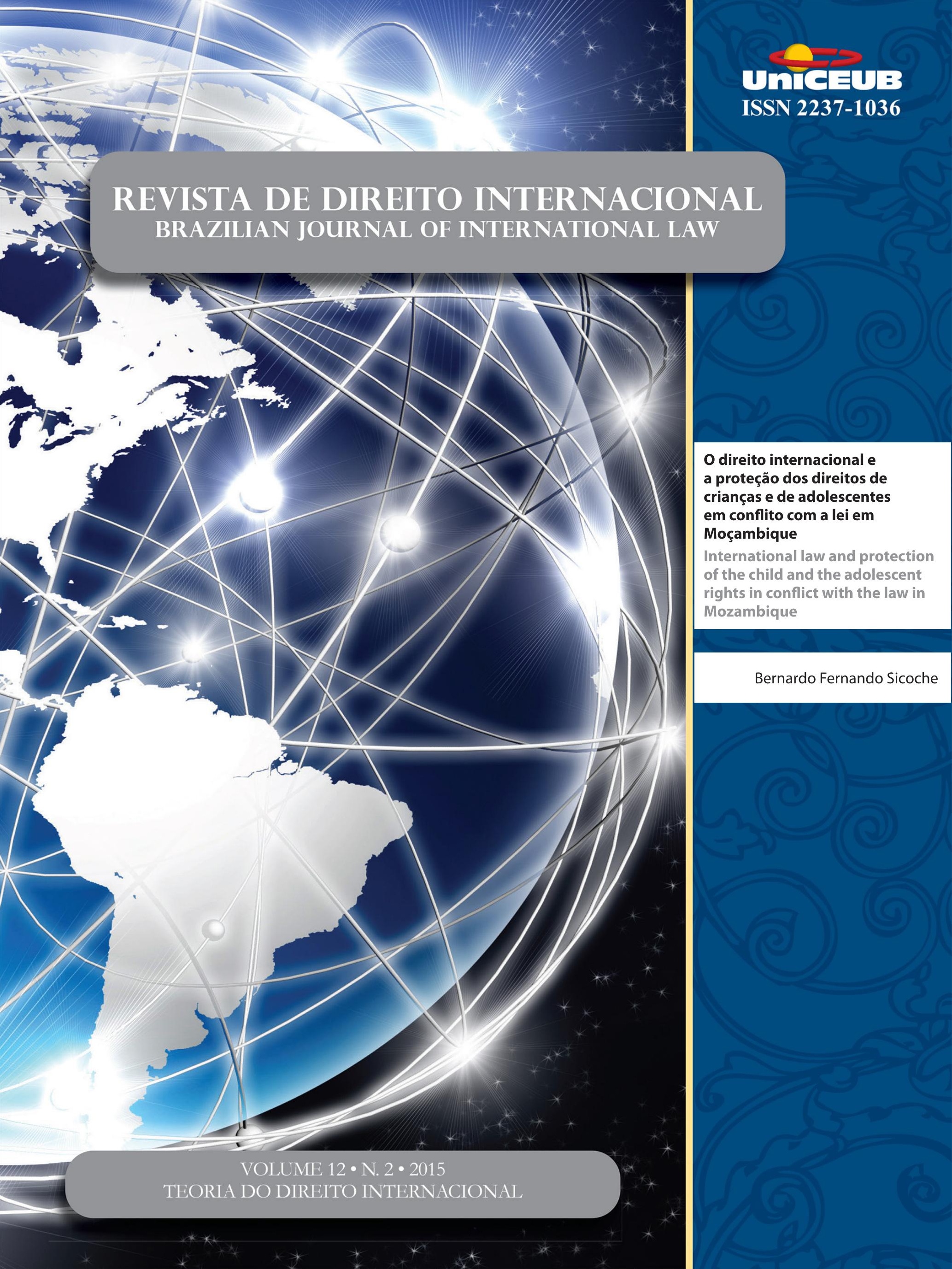




\section{Sumário}

CrôNiCAS DA ATUALIDADE do DiREITo INTERnACIONAL ..................................................... 2 Sarah Dayanna Lacerda Martins Lima, Carina Costa de Oliveira e Erika Braga

CrôniCas do Direito InternaCional dos InVESTIMENTOS ..............................................12 Nitish Monebhurrun

Por que voltar a Kelsen, o jurista do século XX ? 16 Inocêncio Mártires Coelho

O Princípio da Efetividade como conteúdo da norma fundamental (GrundNorm) DE KELSEN

Carlos Alberto Simões de Tomaz e Renata Mantovani de Lima

A JURIDIFICAÇÃo DE CONFLITOS POLÍTICOS NO DIREITO INTERNACIONAL PÚBLICO CONTEMPORÂ-

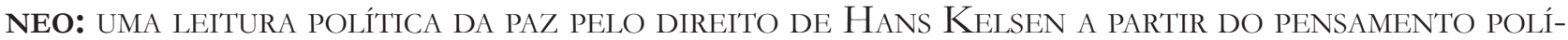
TICO De Claude Lefort

Arthur Roberto Capella Giannattasio

O SINCRETISMO TEÓRICO NA APROPRIAÇÃO DAS TEORIAS MONISTA E DUALISTA E SUA QUESTIONÁVEL UTILIDADE COMO CRITÉRIO PARA A CLASSIFICAÇÃO DO MODELO BRASILEIRO DE INCORPORA-

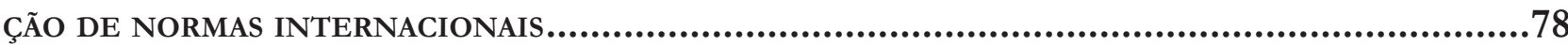
Breno Baía Magalhães

Direito Global em Pedaços: Fragmentação, Regimes e Pluralismo .98 Salem Hikmat Nasser

Por uma TeOria JURÍdica da INTEGRaÇão REgIONAL: A INTER-RELAÇÃO DiREITO INTERNO, DiREITO INTERNACIONAL PÚBLICO E DIREITO DA INTEGRAÇÃO Jamile Bergamaschine Mata Diz e Augusto Jaeger Júnior

A teOria DA INTERCONSTITUCIONALIDADE: UMA ANÁlISE COM BASE NA AMÉRICA LATINA...........160 Daniela Menengoti Ribeiro e Malu Romancini 
O DIÁLOGO HERMENÊUTICO E A PERGUNTA ADEQUADA À APLICAÇÃo DOS TRATADOS INTERNACIONAIS DE DIREITOS HUMANOS NO BRASIL: CAMINHOS PARA O PROCESSO DE INTERNACIONALIZAÇÃO

DA CONSTITUIÇÃO...................................................................................... 176

Rafael Fonseca Ferreira e Celine Barreto Anadon

O DIREITO COMPARADO NO STF: INTERNACIONALIZAÇÃO DA JURISDIÇÃO CONSTITUCIONAL BRASILEIRA

Carlos Bastide Horbach

THE PHILOSOPHY OF INTERNATIONAL LAW IN CONTEMPORARY SCHOLARSHIP: OVERCOMING NE-

GLIGENCE THROUGH THE GLOBAL EXPANSION OF HUMAN RIGHTS

Fabrício Bertini Pasquot Polido, Lucas Costa dos Anjos e Vinícius Machado Calixto

OpORTUNIDADES E DESAFIOS DAS TWAIL NO CONTEXTO LATINO-AMERICANO A PARTIR DE PERSPECTIVAS DOS POVOS INDÍGENAS AO DIREITO INTERNACIONAL

Fernanda Cristina de Oliveira Franco

Por Que uma ANÁlise ECONÔMICA Do DIREITO INTERNACIONAL PÚBLICO? DESAFIOS E PERSPECTIVAS DO MÉTODO NO BRASII

Gustavo Ferreira Ribeiro e Jose Guilherme Moreno Caiado

ANÁliSE ECONÔMICA do DIREITO INTERNACIONAL .263 Michele Alessandra Hastreiter e Luís Alexandre Carta Winter

RACIONALIDADE ECONÔMICA E OS ACORDOS BILATERAIS DE INVESTIMENTO 284 Michele Alessandra Hastreiter e Luís Alexandre Carta Winter

LOOKING FOR A BRICS PERSPECTIVE ON INTERNATIONAL LAW .304 Gabriel Webber Ziero

A INFLUÊNCIA DO DIREITO DESPORTIVO TRANSNACIONAL NO ORDENAMENTO JURÍDICO BRASILEIRO: DA REPRODUÇÃO DE NORMAS À APLICAÇÃO DIRETA PELA JURISDIÇÃO ESTATAL.......................3324 Tiago Silveira de Faria

CONVENCIONALIZAÇÃo DO DIREITO CIVIL: A APLICAÇÃo DOS TRATADOS E CONVENÇÕES INTERNACIONAIS NO ÂMBITO DAS RELAÇÕES PRIVADAS . 
NATIONAL JUdGES AND COURTS AS INSTITUTIONS FOR GLOBAL ECONOMIC GOVERNANCE 356

Juízes e tribunais nacionais como instituições para a governança global 356 Camilla Capucio

Is Trade Governance Changing? 371 Alberto do Amaral Júnior

OS FUNDOS ABUTRES: MEROS PARTICIPANTES DO CENÁRIO INTERNACIONAL OU SUJEITOS PERANTE O DIREITO INTERNACIONAL? 384

Guilherme Berger Schmitt

SHAREHOLDER AGREEMENTS IN PUBLICLY TRADED COMPANIES: A COMPARISON BETWEEN THE

U.S. AND BRAZIL. 402 Helena Masullo

REgulaÇÃo DO INVESTIMENTO ESTRANGEIRO DIRETO NO BRASIL: DA RESISTÊNCIA AOS TRATADOS BILATERAIS DE INVESTIMENTO À EMERGÊNCIA DE UM NOVO MODELO REGULATÓRIO 421 Fabio Morosini e Ely Caetano Xavier Júnior

DA QUALIFICAÇÃo JURÍDiCA dAS Distintas FORMAS DE PRESTAÇão TECNOLÓGICA: BREVE ANÁLISE DO MARCO REGULATÓRIO INTERNACIONAL

Daniel Amin Ferraz

REDEFINING TERRORISM: THE DANGER OF MISUNDERSTANDING THE MODERN WORLD'S GRAVEST THREAT

Jennifer Breedon

As EXECUÇões SELETIVAS E A RESPONSABILIZAÇÃo DE AGENTES TERRORISTAS 485 Alexandre Guerreiro

INTERNATIONAL CRIMINALS AND THEIR VIRTUAL CURRENCIES: THE NEED FOR AN INTERNATIONAL EFFORT IN REGULATING VIRTUAL CURRENCIES AND COMBATING CYBER CRIME Joy Marie Virga

Criminalidad transnacional organizada en el Ámbito del MERCOSUR: ¿Hacia un Derecho Penal Regional?. .528 Nicolás Santiago Cordini e Mariano Javier Hoet 
RUMO À INTERNACIONALIZAÇÃo DA PROTEÇÃO PENAL DO MEIO AMBIENTE: DOS ECOCRIMES AO ECOCÍDIO

Kathia Martin-Chenut, Laurent Neyret e Camila Perruso

Engaging the U.N. Guiding Principles on Business and Human Rights: the inter-AMERICAN COMMISSION ON HUMAN RIGHTS \& THE EXTRACTIVE SECTOR 571 Cindy S. Woods

O DIREITO HUMANO À COMUNICAÇÃo PRÉVIA E PORMENORIZADA DAS ACUSAÇÕES NOS PROCESSOS administrativos: O desprezo do Superior Tribunal de Justiça ao Pacto de San José da Costa Rica e À Corte Interamericana de Direitos Humanos .590

Daniel Wunder Hachem e Eloi Pethechust

A responsabilidade internacional do Brasil em FaCe do CONTRole de ConVENCionaliDADE EM SEDE DE DIREITOS HUMANOS: CONFLITO DE INTERPRETAÇÃO ENTRE A JURISDIÇÃO DA Corte Interamericana de Direitos Humanos e o Supremo Tribunal Federal quanto a LEI DE ANISTIA 612

Carla Ribeiro Volpini Silva e Bruno Wanderley Junior

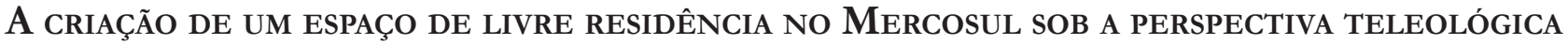
DA INTEGRAÇÃo REGIONAL: ASPECTOS NORMATIVOS E SOCIAIS DOS ACORDOS DE RESIDÊNCIA ....... 631

Aline Beltrame de Moura

A funcionalização como tendênCia evolutiva do Direito Internacional e sua conTRIBUIÇÃO AO REGIME LEGAL DO BANCO DE DADOS DE IDENTIFICAÇÃO DE PERFIL GENÉTICO NO BRASIL

Antonio Henrique Graciano Suxberger

O DIREITO INTERNACIONAL E A PROTEÇÃO DOS DIREITOS DE CRIANÇAS E DE ADOLESCENTES EM CONFLITO COM A LEI EM MOÇAMBIQUE

Bernardo Fernando Sicoche

ObTenÇão de PRovas no EXTERIOR: PARA ALÉM dA LEX FORI E LEX DiLigENTIAE. .685 André De Carvalho Ramos 
A Slight Revenge and a Growing Hope for Mauritius and the Chagossians: The UNClos Arbitral Tribunal's Award of 18 March 2015 on Chagos Marine Protected Area (Mauritius v. United Kingdom)

Géraldine Giraudeau

ANÁLISE DA RESPONSABILIDADE INTERNACIONAL DA UCRÂNIA POR VIOLAÇÃo DOS DIREITOS HUmanos na QUeda do voo da Malaysia Airlines (MH17). .728

Daniela Copetti Cravo

NatureZa JURÍdica do DESENVOLVIMENTO SUSTENTÁVEL No DIREITO INTERNACIONAL ........739 Pedro Ivo Diniz

A INFLUÊNCIA Da SOFT LAW NA FORMaÇão do DiREITo AMBIENTAL .767 Leonardo da Rocha de Souza e Margareth Anne Leister

As COMPLICADAS INTER-RELAÇÕES ENTRE OS SISTEMAS INTERNOS E INTERNACIONAIS DE PROTEÇãO DO DIREITO AO MEIO AMBIENTE SADIO. 785 José Adércio Leite Sampaio e Beatriz Souza Costa 


\title{
O direito internacional e a proteção dos direitos de crianças e de adolescentes em conflito com a lei em Moçambique*
}

\author{
International law and protection of the child \\ and the adolescent rights in conflict with the \\ law in Mozambique
}

Bernardo Fernando Sicoche ${ }^{* *}$

\section{Resumo}

O objetivo deste artigo é analisar os mecanismos e os instrumentos de proteção da criança e do adolescente em conflito com a lei em Moçambique, à luz das leis internas e do Direito Internacional. O enfoque é propor mecanismos de apoio e de promoção da melhoria do atendimento da criança e do adolescente em conflito com a lei penal em Moçambique, no que concerne aos procedimentos socioeducativos e processuais. Primeiramente, abordam-se aspectos conceptuais, os fundamentos teóricos e jurídicos de proteção da criança e do adolescente em conflito com a lei. Em seguida faz-se analisam-se instrumentos internacionais de proteção das crianças e dos adolescentes autores de ato infracional, alguns deles ratificados pelo governo de Moçambique. Analisa-se, também, o impacto dessas normas na realidade moçambicana. Finalmente, discutem-se os procedimentos adotados na justiça infantil, atualmente, com vista a proteção das crianças e adolescentes em Moçambique. Em termos metodológicos, optou-se pela pesquisa bibliográfica (coleta de dados secundários - materiais analisados, relatórios, revistas, artigos, leis, estatutos, livros e folhetos). A conclusão, que se chega neste artigo, é de que existem vários instrumentos internacionais e nacionais que visam à proteção de crianças e adolescentes em conflito com a lei. Contudo, a inobservância dessas leis pelos agentes encarreguem para velar sobre a justiça infantil, devido, por um lado, ao desconhecimento dessa matéria, por outro lado, devido à falta de coordenação e cooperação no âmbito da execução dos procedimentos tendentes a proteção dos menores visados; à falta de alternativas de detenção para menores ofensores; e à falta de acesso à justiça juvenil. A formação e a capacitação jurídica em matéria do direito da criança e do adolescente, aos agentes ligados ao setor da justiça de menores, podem contribuir para uma maior observância e respeito pelas normas nacionais e internacionais sobre os direitos da criança e a respectiva justiça infantil.

* Recebido em 03/09/2015 Aprovado em 07/12/2015

** Doutorando em Ciência Política na Universidade Federal do Rio Grande do Sul. Mestre em Direito pela Universidade Federal do Rio Grande do Sul. Bolsista do Programa Estudantes-Convênio de Pós-Graduação PEC-PG, da CAPES/CNPq - Brasil. E-mail: bernardosicoche@yahoo.com.br.
Palavras-chave: Criança e adolescente em conflito com a lei. Direitos da criança e do adolescente. Direito internacional. Justiça de menores. 


\section{Abstract}

The objective of this paper is to analyze the mechanisms and child protection instruments and teenagers in conflict with the law in Mozambique, in the light of domestic laws and international law. The focus is to propose mechanisms to support and promote improved child care and adolescents in conflict with the law in Mozambique, with regard to youth and procedural requirements. First, we discuss conceptual aspects, theoretical and legal foundations child protection and adolescents in conflict with the law. Then makes an analysis of international instruments for the protection of children and teenager who infraction, some of them ratified by the Government of Mozambique. It analyzes also the impact of these standards on the Mozambican reality. Finally, the procedures adopted are discussed in children's justice, currently, in order to protect children and teenagers in Mozambique. In terms of methodology we were chosen literature (secondary data collection - analyzed materials, reports, journals, articles, laws, statutes, books and leaflets). The conclusion that is reached in this study is that there are several international and national instruments aimed at protecting children and teenagers in conflict with the law. However, the non-observance to comply with these laws by responsible officers to watch over the children's justice, because on the one hand, the ignorance of this matter, on the other, due to lack of coordination and cooperation in the implementation of procedures to protect the targeted children; the lack of alternatives to detention of minor offenders; and lack of access to juvenile justice. Training and legal training in the field of child and adolescent rights, the agents of the juvenile justice sector can contribute to better compliance and respect for national and international standards on children's rights and their children's justice.

Keywords: Children and Adolescents in conflict with the law. Rights of the child and the adolescent. International law. Minors justice.

\section{INTRODUÇÃO}

A proteção internacional da criança e do adolescente em conflito com a lei na sociedade moderna é um tema de indiscutível centralidade, quer pelo caráter passional dos direitos da criança e interesse que desperta na sociedade, quer pela importância que lhe é devida por cada um dos países e governos signatários da Declaração Universal dos Direitos da Criança. O presente artigo tem como tema "o Direito Internacional e a proteção dos direitos da criança e do adolescente em conflito com a lei em Moçambique" e foi elaborado no âmbito da preocupação pelas atuais formas de tratamentos de menores em conflito com a lei.

A motivação para o tema surge no âmbito das constatações de que, nos últimos anos, nas cadeias moçambicanas, existe a predominância de muitos reclusos com idade inferior a 16 anos. Um estudo realizado pelo Ministério da Justiça de Moçambique em coordenação com o Fundo das Nações Unidas para a Infância (UNICEF), em 2003, revelou que foram visitados 20 estabelecimentos penitenciários e algumas esquadras da polícia. Nesses locais foram entrevistados um total de 106 reclusos com menos de 21 anos de idade, sendo 75 com menos de 18 e 37 com menos de 16 anos de ida$\mathrm{de}^{1}$. Segundo os pesquisadores, entre os entrevistados, estavam ainda "duas crianças de 12 anos de idade na província de Nampula, uma delas estava detida há 16 dias, por posse de droga (marijuana)"'2.

$\mathrm{Na}$ visão de Baleira, os dados estatísticos não espelham de uma forma
clara a magnitude e as características do problema,
mas dentro desse quadro teórico conceitual, os
dados colhidos apontam para a existência de um
número expressivo - entre 25 e $30 \%$ - e cada vez
maior de crianças em situação de conflito com a lei ${ }^{3}$.

Outro estudo sobre as crianças em conflito com a lei, levado a cabo pelo $\mathrm{UNICEF}^{4}$ em 2006, revela que "pelo menos $25 \%$ de todos os reclusos inquiridos tinham menos de 18 anos de idade, e 18\% tinham menos de 16". À luz da lei moçambicana (art. 46 do Código Penal), os menores de 16 anos gozam de uma inimpu-

1 BALEIRA, Sérgio (Coord.). Relatório preliminar da pesquisa sobre "A Criança em Conflito com a Lei". Moçambique: [S.n], abr.de 2003. Consultoria com Save The Children Norway. p. 8.

2 BALEIRA, Sérgio (Coord.). Relatório preliminar da pesquisa sobre "A Criança em Conflito com a Lei". Moçambique: [S.n], abr.de 2003. Consultoria com Save The Children Norway. p. 8.

3 BALEIRA, Sérgio (Coord.). Relatório preliminar da pesquisa sobre "A Criança em Conflito com a Lei". Moçambique: [S.n], abr.de 2003. Consultoria com Save The Children Norway. p. 8

4 FUNDO DAS NAÇÕES UNIDAS PARA A INFÂNCIA. Proteção da criança. Moçambique: UNICEF, 2014. Disponível em: <http://www.unicef.org/mozambique/pt/protection.html $>$. Acesso em 27 set. 2014. 
tabilidade absoluta.

Paralelamente aos dados acima, também foram relatadas várias constatações ligadas à violação dos direitos da criança e do adolescente em conflito com a lei. Dentre vários problemas constatados, destaca-se o descumprimento das normas nacionais e internacionais; a existência de muitas crianças nas cadeias moçambicanas; violação policial contra as crianças e os adolescentes autores de ato infracional; existência de crianças e de adolescentes "sem voz" que passam injustiças graves no seu tratamento e falta de proteção e apoio; inexistência de processos legais claros para casos em que há menores envolvidos; falta de alternativas de detenção para menores ofensores; falta de acesso à justiça juvenil; e a junção de adolescentes e adultos nas mesmas cadeias ${ }^{5}$.

De acordo com Miguel,

em 2013, cerca de 2.300 crianças e adolescentes em conflito com a lei foram mantidos em regime de reclusão, pese embora os crimes de que são acusados sejam considerados de pequena dimensão. Todavia, eles estão a beneficiar de assistência jurídica acompanhada pelos técnicos da justiça moçambicana e do UNICEF. Segundo o Ministério da Justiça, em Moçambique existem 17.000 crianças e adolescentes detidos e o número tende a aumentar, segundo estudos efetuados a nível local e internacional, os quais demonstram ainda que grande parte desse grupo encontra-se nos centros de reabilitação. Enquanto isso, Koenraad Vanormelingen, representante da UNICEF em Moçambique disse que 700.000 crianças vivem em situação de vulnerabilidade no país. O UNICEF está a desenvolver um programa que em parte pretende sensibilizar as comunidades a perceberem que a criança não pode ser vista como criminosa ${ }^{6}$.

Com base nesses dados, verifica-se que o índice dos casos de crianças e de adolescentes autores de ato infracional presos nas cadeias moçambicanas tende a subir. Em relação à ideia de proteção dos direitos da criança e do adolescente, percebe-se que, apesar dos esforços empreendidos, tem fracassado o papel do Estado na busca e proteção dos direitos humanos da criança, na medida em que, os procedimentos atualmente adotados, com vista a aplicação da justiça infantil, no País, co-

5 BALEIRA, Sérgio (Coord.). Relatório preliminar da pesquisa sobre "A Criança em Conflito com a Lei". Moçambique: [S.n], abr.de 2003. Consultoria com Save The Children Norway. p. 6.

6 MANGUE, Reginaldo. Milhares de crianças estão em conflito com a lei no país.Jornal@Verdade, Moçambique, 27 mar. 2014. Disponível em: <http://www.verdade.co.mz/nacional/45093milhares-de-criancas-estao-em-conflito-com-a-lei-no-pais $>$. Acesso em: 10 set. 2014. lidem com as normas internacionais do Direito Público sobre a proteção da criança e adolescente em conflito com a lei.

Por essa razão, neste artigo procura-se relacionar as normas do Direito Internacional com a estrutura e a atuação das instituições moçambicanas encarreguem pela proteção de criança e adolescente em conflito com a lei, num Estado de Direito Moçambicano, segundo consagra a Constituição da República de Moçambique (CRM) de 2004. Nesse sentido, dá-se enfoque à percepção de que, só assegurando a ampla e profunda integração das políticas governamentais e a efetiva articulação dessas políticas com o Direito Internacional e a sociedade civil, pode-se conquistar avanços significativos na realização dos direitos da criança e do adolescente em Moçambique. Ou seja, uma proteção efetiva da criança e do adolescente pode mitigar os riscos e as vulnerabilidades que contribuem para os abusos da justiça infantil.

A Convenção sobre os Direitos da Criança de 1989 reafirma o fato de as crianças, devido à sua vulnerabilidade, necessitarem de uma proteção e de uma atenção especial e, sublinha de forma particular a responsabilidade fundamental do Estado, no que diz respeito aos cuidados e proteção. Dispõe, ainda, a necessidade de proteção jurídica e não jurídica de adolescentes e o papel vital da cooperação internacional para que os direitos da criança e de adolescente sejam uma realidade.

A necessidade de garantir uma proteção especial à criança foi enunciada, pela primeira vez, na Declaração de Genebra de 1924 sobre os Direitos da Criança e seguidamente na Declaração dos Direitos da Criança adotada pelas Nações Unidas em 1959. Também foi reconhecida pela Declaração Universal dos Direitos do Homem; pelo Pacto Internacional sobre os Direitos Civis e Políticos; pelo Pacto Internacional sobre os Direitos Econômicos, Sociais e Culturais (art. 10); e pelos estatutos e instrumentos pertinentes das agências especializadas e organizações internacionais que se dedicam ao bem-estar da criança.

Assim, na busca pela garantia dos direitos da criança e do adolescente em conflito com a lei, estabelece-se como prioridade, no presente artigo, a atenção no estudo de mecanismos de apoio e de promoção da melhoria do atendimento da criança e do adolescente em conflito com a lei penal. O enfoque é propor mecanismos de reforço da justiça de menores em conflito com a lei, no que concerne aos procedimentos socioeducativos e 
processuais.

Dessa forma, traçou-se os seguintes objetivos como linhas de orientação para a materialização do artigo: $O b$ jetivo Geral: analisar o sistema de atendimento sociopedagógico e protetivo às crianças e aos adolescentes em conflito com a lei em Moçambique, a luz das normas nacionais e internacionais; Objetivos Especificos: avaliar os mecanismos nacionais e internacionais do Direito Internacional para a proteção da criança e do adolescente; propor algumas medidas para o melhoramento de atendimento a criança e ao adolescente infrator.

Este artigo está estruturado em quatro seções: na primeira abordam-se aspectos conceptuais e os fundamentos teóricos e jurídicos de proteção da criança e do adolescente em conflito com a lei; na segunda seção, descreve-se os instrumentos internacionais de proteção da criança e do adolescente em conflito com a lei e seus respectivos impactos na realidade moçambicana; a terceira seção aborda a justiça infantil e sua proteção em crianças e adolescentes em Moçambique; na quarta e última seção apresenta-se as considerações finais que resultam da inferência feita com base nas constatações da pesquisa e nas referências bibliográficas consultadas.

\section{Conceito e fundamentos teóricos e JURÍDICOS DE PROTEÇÃO DA CRIANÇA E DO ADOLESCENTE EM CONFLITO COM A LEI}

O termo 'criança em conflito com a lei' "é uma expressão conceitual que envolve elementos que representam realidades sociais de grande complexidade, nomeadamente a 'criança', a 'lei' e, entre estes, o próprio 'estado de conflito' que o significado da expressão encerra"7. As Regras de Beijing, que não só estabelecem garantias de proteção aos jovens, como também um sistema justo, humano e digno para todos menores, na sua Regra 2.2, consideram criança ou adolescente autor de ato infracional "qualquer criança ou jovem acusado de ter cometido um delito ou considerado culpado de ter cometido um delito" ${ }^{8}$.

7 BALEIRA, Sérgio (Coord.). Relatório preliminar da pesquisa sobre "A Criança em Conflito com a Lei”. Moçambique: [S.n], abr.de 2003. Consultoria com Save The Children Norway. p. 25.

8 ASSEMBLEIA GERAL DAS NAÇÕES UNIDAS. Regras minimas das Nações Unidas para a administração da justiça de menores (Regras de Beïing). 1985. Disponível em: <http://www.gddc.pt/direitos-
Segundo Baleira,

o estado de conflito com a lei representa, a priori, a não conformidade entre a conduta ou comportamento do indivíduo com as regras ou normas formal ou informalmente institucionalizadas numa sociedade ou comunidade?

Assim, considera-se que "a criança está em conflito com a lei quando esta rompe com as leis estabelecidas e/ou adquire um comportamento que não corresponde às expectativas da sociedade" ${ }^{" 10}$. Ao passo que o conceito de menor, criança e adolescente varia de um país para o outro. Algumas nações tendem a fazer coincidi-lo com a definição adotada por algumas organizações internacionais e outros tendem a separar os três termos.

Nas teorias modernas, alguns autores tendem, também, a estabelecer diferenças concepcionais entre criança e adolescente. Por exemplo, Frota afirma que,

de um modo geral, existe a compreensão de que ser criança resume-se em ser feliz, alegre, despreocupado, ter condições de vida próprias ao seu desenvolvimento, ou seja, a infância é considerada o melhor tempo da vida [...]. Já que a adolescência se configura como um momento em que, naturalmente, o indivíduo tornase alguém muito chato, difícil de se lidar e que está sempre criando confusão e vivendo crises [...]. Deste modo, existe uma leitura de senso comum que costuma colocar a criança vivendo o melhor momento da vida e o adolescente, uma fase difícil para ele e para quem convive com ele. ${ }^{11}$

Frota, ainda explica que etimologicamente "a palavra infância vem do latim, infância, e refere-se ao indivíduo que ainda não é capaz de falar. Essa incapacidade, atribuída à primeira infância, estende-se até os sete anos, que representa a idade de razão"12. Com mesmo entendimento Àries esclarece que:

a primeira idade é a infância que planta os dentes, e essa idade começa quando a criança nasce e dura

humanos/textos-internacionais-dh/tidhuniversais/dhaj-NOVOregrasBeijing.html>. Acesso em: 01 fev. 2016.

9 BALEIRA, Sérgio (Coord.). Relatório preliminar da pesquisa sobre "A Criança em Conflito com a Lei”. Moçambique: [S.n], abr.de 2003. Consultoria com Save The Children Norway. p. 29.

10 BALEIRA, Sérgio (Coord.). Relatório preliminar da pesquisa sobre "A Criança em Conflito com a Lei”. Moçambique: [S.n], abr.de 2003. Consultoria com Save The Children Norway. p. 29.

11 FROTA, Ana Maria Monte Coelho. Diferenças concepções da infância e adolescência: a importância da historicidade para sua construção. Estudos e Pesquisas em Psicologia, Rio de Janeiro, v. 7, n. 1, p. 147-160, abr. 2007. p. 148.

12 FROTA, Ana Maria Monte Coelho. Diferenças concepções da infância e adolescência: a importância da historicidade para sua construção. Estudos e Pesquisas em Psicologia, Rio de Janeiro, v. 7, n. 1, p. 147-160, abr. 2007. p. 150. 
até os sete anos, e nessa idade aquilo que nasce é chamado enfant (criança), que quer dizer não falante, pois nessa idade a pessoa não pode falar bem nem formar perfeitamente suas palavras, pois ainda não tem seus dentes bem ordenados nem firmes. Após a infância, vem a segunda idade, que chama-se puerita e é assim chamada porque nessa idade a pessoa é ainda como a menina do olho, e essa idade dura até os 14 anos. $^{13}$

Em relação ao termo adolescente, Eisenstein, explica que

os limites cronológicos da adolescência são definidos pela Organização Mundial de Saúde (OMS) entre 10 e 19 anos (adolescentes) e pela Organização das Nações Unidas (ONU) entre 15 e 24 anos (youth), critérios estes usados principalmente para fins estatísticos e políticos ${ }^{14}$.

Seguidamente, essa autora esclarece que "na maioria dos países, o conceito de maioridade do ponto de vista legal é estabelecido aos 18 anos, mas outros critérios existem e permanecem flexíveis e confusos, de acordo com os costumes e culturas locais" ${ }^{\prime 1}$.

Autores como Marcelli e Braconnier definem a adolescência como uma "fase, um período, uma passagem da infância à fase adulta" ${ }^{16}$. Ideias semelhantes são expressas por Habigzang e Caminha na assertiva segundo a qual:

a infância e a adolescência são etapas do ciclo de vida nas quais o indivíduo desenvolve as capacidades cognitivas, afetivas e físicas [...] habilidades sociais [...]. Crianças e adolescentes são considerados sujeitos em condição peculiar de desenvolvimento, necessitando cuidados especiais que garantam a sua proteção e o desenvolvimento de suas potencialidades. ${ }^{17}$

Nos termos da Convenção sobre os Direitos da Criança adotada pela Assembleia Geral das Nações Unidas em 20 de novembro de 1989, a criança é definida

13 ARIÈS, Philippe. História social da criança e da família. Tradução de Dora Flaksman. 2. ed. Rio de Janeiro: LTC, 1981. p. 36.

14 EISENSTEEIN, Evelyn. Adolescência: definição, conceitos e critérios. Adolescência \& Saúde, Rio de Janeiro, v. 2, n. 2, p. 1-6, jun. 2005. p. 6.

15 EISENSTEEIN, Evelyn. Adolescência: definição, conceitos e critérios. Adolescência \& Saúde, Rio de Janeiro, v. 2, n. 2, p. 1-6, jun. 2005. p. 6

16 MARCELLI; BRACONNIER, 1986 apud JACOBINA, Olga Maria Pimentel; COSTA, Liana Fortunato. Para não ser bandido: Trabalho e Adolescentes em conflito com a lei. Cadernos de Psicologia Social do Trabalho, São Paulo, v. 10, n. 2, p. 95-110, 2007. p. 97.

17 HABIAGZANG, Luísa Fernanda; CAMINHA, Renato Maiato. Abuso sexual contra crianças e adolescentes: conceituação e intervenção clínica. São Paulo: Casa do Psicólogo, 2004. p. 19. como todo o ser humano com menos de dezoito anos de idade, exceto se a lei nacional confere a maioridade mais cedo. Neste instrumento internacional, sublinha-se a necessidade de "a idade limite abaixo da qual não deve ser permitido privar uma criança de liberdade deve ser fixada em lei" "18. Notou-se, também, nessa Convenção que o termo "criança" é utilizado sem distinção com o de menor e de adolescente.

Situação idêntica verifica-se nas Regras Mínimas das Nações Unidas para a Administração de Justiça de Menores (Regras de Beijing). Essa norma internacional opta por usar o termo "menor", entendido como "qualquer criança ou jovem que, em relação ao sistema jurídico considerado, pode ser punido por um delito, de forma diferente da de um adulto", ao passo que as Regras Mínimas das Nações Unidas para a proteção dos jovens privados de liberdades usam o termo "jovem", compreendido como "uma pessoa de idade inferior a 18 anos". Contudo, destaca-se nessa norma a necessidade de em cada país a lei estabelecer de forma explícita a idade-limite antes da qual o jovem não poderá ser privado de sua liberdade individual.

Em alguns países, faz-se uma distinção clara entre os termos menor, criança e adolescente. Por exemplo, o Estatuto da Criança e do Adolescente ${ }^{19}$ do Brasil (ECA) que dispõe sobre a proteção integral à criança e ao adolescente, estabelece uma diferença explícita entre criança e adolescente. À luz do ECA “considera-se criança, a pessoa até doze anos de idade incompletos e, adolescente aquela entre doze (completos) e dezoito anos de idade" (art. 2o, ECA). O parágrafo único deste artigo estabelece que, nos casos expressos em lei, aplica-se excepcionalmente o ECA às pessoas entre dezoito e vinte e um anos de idade.

Noutros países, como é o caso de Moçambique, não se faz distinção clara, confundindo-se os três termos, como sinônimos, a semelhança com o conceito adotado na Carta Africana dos Direitos e Bem-Estar da Criança. $\mathrm{O}$ art. $3^{\circ}$ da Lei n. ${ }^{\circ}$ 7/2008, dispõe que, se considera criança, toda pessoa menor de dezoito anos de idade. Mas, nos casos expressamente previstos, a mesma lei aplica-se, também, aos menores com mais de dezoito e

18 ASSEMBLÉIA GERAL DAS NAÇÕES UNIDAS. Regras das Nações Unidas para a proteção dos menores privados de liberdade. Disponível em: <http://www.rolim.com.br/2002/_pdfs/066.pdf>. Acesso em: 20 set. 2014.

19 BRASIL. Estatuto da Criança e do Adolescente. 7. ed. Brasília: Câmara dos Deputados, 2010. 
menos de vinte e um anos de idade. Esta definição está em conformidade com os princípios do Direito Internacional, como explica Issá, ao aludir que:

No que se refere ao conceito de criança, depois
de considerados vários fatores atinentes ao
desenvolvimento da criança e ao estabelecimento
na Convenção sobre os Direitos da Criança,
decidiu-se acolher a regra estabelecida no Direito
Internacional, que considera criança, todo o menor
de 18 anos. Entendeu-se, entretanto, que deveria
estender a aplicação da lei aos maiores de 18 e
menores de 21 , sempre que se justifique. ${ }^{20}$

A Resolução n 32/2006 de Conselho de Ministros de Moçambique, que define "Estratégia de Desenvolvimento Integral da Juventude", estabelece uma diferenciação dos termos criança e jovem. Consta nessa resolução que jovem é todo o indivíduo moçambicano que se encontra na faixa etária de 15 a 35 anos de idade, o que se subentende que indivíduo com idade inferior a 15 anos seja considerado criança. No entanto, é importante destacar que o Código Civil de Moçambique (CC) define a maioridade civil em 21 anos (art. 130 do CC). Antes de se completar esta idade, salvo algumas exceções admitidas pelo art. 124 do CC, o exercício de direitos civis carece de consentimento dos representantes legais.

A Constituição da República de Moçambique (CRM) fixa a maioridade política em 18 anos - idade pela qual uma pessoa tem o dever e o direito de votar e de ser votada (exercício da cidadania). Contudo, no que diz respeito à responsabilidade criminal, que se traduz na imputabilidade ou inimputabilidade criminal, o Código Penal moçambicano (CP), determina que gozam de inimputabilidade absoluta "Os menores de 16 anos" (alínea a, do art. 46 do CP). E possuem a inimputabilidade relativa, "Os menores que, tendo dezesseis anos e menos de vinte e um, tiverem precedido sem discernimento" (alínea a, n. ${ }^{\circ}$, art. 47 do CP).

Pires e Nery Filho relacionam a questão de imputabilidade à responsabilidade. $\mathrm{Na}$ visão desses autores, "a imputação, ou imputabilidade, estabelece uma relação causal entre um sujeito e uma ação, no caso uma ação delituosa. [...]. Por sua vez, a responsabilidade, por outro lado, relaciona-se às consequências legais do ato praticado" 21 . Entretanto, o legislador moçambicano fi-

20 ISSÀ, Abdul Carimo Mahomed. Lei de base de proteção da criança, lei da organização jurisdicional de menores e lei sobre o tráfico de pessoas. Maputo: Central Impressora e Editora de Maputo, 2008. p. 18.

21 PERES, Maria Fernanda Tourinho; NERY FILHO, Antônio. A doença mental no direito penal brasileiro: inimputabilidade, irre- xou em 16 anos a maioridade criminal (a imputabilidade), que se entende como sendo a idade a partir da qual se considera que a criança já goza da necessária liberdade e inteligência para distinguir entre o bem e o mal. Nesse sentido, Marques, afirma que:

O menor, pelo seu desenvolvimento mental ainda incompleto, não possui a maturidade suficiente para dirigir a sua conduta com poder de autodeterminação em que se descubra, em pleno desenvolvimento, os fatores intelectivos e volitivos que devem nortear o comportamento humano. Daí entender-se que o menor não deve considerar-se um imputável. ${ }^{22}$

A nível teórico defende-se que o conceito da criança é refletido por uma visão subjetiva, segundo a qual, o ser criança pode significar, antes de mais nada, a incapacidade biológica e/ou psicológica de um indivíduo, de realizar determinado tipo de atividades classificadas sociológica e/ou legalmente como sendo de adultos e por essa razão, não se lhe deve atribuir tal responsabilidade $^{23}$. À luz da Legislação moçambicana (Código Penal e Civil), encontram-se, objetivamente, três classes ou categorias de crianças ou de adolescentes, nomeadamente: criança menor de 16 anos de idade - legalmente inimputável; criança maior de 16 e menor de 18 anos de idade - penalmente imputável com pena diminuída e civilmente inimputável; criança maior de 18 e menor de 21 anos de idade - penalmente imputável e civilmente inimputável ${ }^{24}$.

Essas divisões em categorias provêm do entendimento de que a pessoa, em certa idade, ainda não goza de uma sanidade mental apta para responder com as suas responsabilidades, como afirma Bitencourt:

A falta de sanidade mental ou a falta de maturidade
mental, que é a hipótese da menoridade (18 anos),
podem levarao reconhecimento dainimputabilidade,
pela incapacidade da culpabilidade. [...]. A
imaturidade mental, isoladamente, esgota o conceito
da inimputabilidade, porque, por presunção
legal, o menor de dezoito anos é mentalmente
imaturo e, consequentemente, incapaz de qualquer

sponsabilidade, periculosidade e medida de segurança. História, Ciências, Saúde - Manguinhos. Rio de Janeiro, v. 9, n. 2, p. 335-355, maio/ ago. 2002. p. 339.

22 MARQUES, José Frederico. Tratado de direito penal. Campinas: Bookseller, 1997. p. 222.

23 BALEIRA, Sérgio (Coord.). Relatório preliminar da pesquisa sobre "A Criança em Conflito com a Lei”. Moçambique: [S.n], abr.de 2003. Consultoria com Save The Children Norway. p. 25.

24 BALEIRA, Sérgio (Coord.). Relatório preliminar da pesquisa sobre "A Criança em Conflito com a Lei”. Moçambique: [S.n], abr.de 2003. Consultoria com Save The Children Norway. p. 27. 
culpabilidade. Nessa hipótese, é suficiente que se faça a comprovação da idade do menor, isto é, do aspecto puramente biológico. ${ }^{25}$

Couto compartilha também com a ideia de imputabilidade da criança, ao afirmar que "[...] a inimputabilidade em razão da idade se fundamenta nesta falta de maturidade emocional a par de uma incapacidade de controle de impulso de acordo com os valores adequados" ${ }^{26}$. Em outras palavras, Couto destaca que "a censura jurídico-penal do adulto possuidor de uma personalidade totalmente formada não existe para o menor, no qual se verifica uma certa falta de maturidade e entendimento de estruturas e valores ético-sociais" ${ }^{27}$.

$\mathrm{O}$ ato criminal praticado pela criança ou adolescente pode ser uma experiência de busca de sentido e de limite, da mesma maneira que pode ser um equivalente depressivo, uma maneira de disfarçar a depressão decorrente de abandono afetivo, emocional e familiar do menor infrator ${ }^{28}$. Daí decorre inimputabilidade em razão da menoridade.

\section{INSTRUMENTOS INTERNACIONAIS DE PROTEÇÃO DA CRIANÇA E DO ADOLESCENTE EM CONFLITO COM A LEI}

A necessidade e a exigência de reconhecimento da garantia de uma proteção especial à criança foram enunciadas, pela primeira vez, na Declaração de Genebra de 1924 sobre os Direitos da Criança. Mas, a partir da Declaração Universal dos Direitos Humanos, adotada em 1948, que comunidade internacional, por intermédio da Organização das Nações Unidas (ONU), vem construindo uma série de instrumentos normativos, em que são registrados mecanismos de controle e cooperação, visando assegurar a não violação dos direitos fundamentais do ser humano, em especial da criança.

25 BITENCOURT, Cezar Roberto. Código Penal comentado. São Paulo: Saraiva, 2002. p. 103.

26 COUTO, Isabel Luís do. O problema da idade da imputabilidade penal. 2012. 56 f. Tese (Mestrado) - Programa de Pós-Graduação do Centro Regional do Porto, Escola de Direito, Universidade Católica Portuguesa, Porto, 2012. p. 40.

27 COUTO, Isabel Luís do. O problema da idade da imputabilidade penal. 2012. 56 f. Tese (Mestrado) - Programa de Pós-Graduação do Centro Regional do Porto, Escola de Direito, Universidade Católica Portuguesa, Porto, 2012. p. 41.

28 TRINDADE, Jorge. Delinquência juvenil: competência transdisciplinar. 3. ed. Porto Alegre: Livraria do Advogado, 2002. p. 74.
É nessa perspectiva que o artigo 10 do Pacto Internacional de Direitos Econômicos, Sociais e Culturais, adotado pela Assembleia Geral das Nações Unidas em 1966, determina claramente que os Estados “devem adotar medidas especiais de proteção e de assistência que devem ser tomadas em benefício de todas as crianças e adolescentes, sem discriminação alguma derivada de razões de paternidade ou outras". Já o artigo 10 do Pacto Internacional sobre os Direitos Civis e Políticos de 1966 faz referências explícitas às crianças e aos adolescentes em conflito com a lei e, estabelece de forma clara os mecanismos de tratamento aos jovens nas mãos da justiça, aguardando o julgamento e julgados, como pode se observar na assertiva abaixo:

\section{As pessoas jovens processadas deverão ser separadas das adultas e julgadas o mais rápido possível. O regime penitenciário consistirá em um tratamento cujo objetivo principal seja a reforma e a reabilitação moral dos prisioneiros. Os delinquentes juvenis deverão ser separados dos adultos e receber tratamento condizente com sua idade e condição jurídica ${ }^{29}$.}

No entanto, o principal o instrumento jurídico mais transcendente, construído pela comunidade internacional para proteger os menores de idade autores de ato infracional é a Convenção Internacional sobre os Direitos da Criança, adotada pela Assembleia Geral da ONU em 1989. Esta Convenção dispõe sobre a Doutrina da Proteção Integral, demandando a observância dos princípios da excepcionalidade e brevidade da privação de liberdade da criança e do adolescente e a instituição da justiça juvenil.

A Convenção sobre os Direitos da Criança (CDC), a Carta Africana sobre os Direitos e Bem-estar da Criança apresentam uma ampla análise da necessidade de proteção da criança. Estes ordenamentos jurídicos reconhecem que as crianças são vulneráveis a violações dos seus direitos humanos básicos, e, consequentemente, lhes concede o direito fundamental à proteção jurídica e social, antes e após o nascimento.

De acordo com Tânia da Silva Pereira, a Convenção representa "um consenso de que existem alguns direitos básicos universalmente aceitos e que são essenciais para o desenvolvimento completo e harmonioso

29 ORGANIZAÇÃO DAS NAÇÕES UNIDAS. Pacto Internacional dos Direitos Civis e Politicos (1966). Disponível em: <http://www. oas.org/dil/port/1966\%20Pacto $\% 20$ Internacional $\% 20$ sobre $\% 20$ Direitos $\% 20$ Civis $\% 20 \mathrm{e} \% 20 \mathrm{Pol} \% \mathrm{C} 3 \%$ ADticos.pdf>. Acesso em: 25 jun. 2012. 
da criança" ${ }^{30}$. Para essa autora, a Convenção também "representa, em definitivo, o instrumento jurídico internacional mais transcendente para a promoção e o exercício dos direitos da criança" ${ }^{31}$. Na mesma perspectiva se insere a Veronese, ao dispor que o cumprimento das normas constantes naquela Convenção é de caráter obrigatório pelos Estados, porque a norma nela instituída "tem natureza coercitiva e exige de cada Estado-Parte que a subscreve e ratifica um determinado posicionamento. [...] tem força de lei internacional e, assim, cada Estado não poderá violar seus preceitos, como também deverá tomar as medidas positivas para promovê-los" ${ }^{\prime 32}$.

A Convenção sobre os Direitos da Criança (CDC) $)^{33}$ estabelece alguns princípios basilares que norteiam o tratamento das crianças e dos adolescentes em conflito com a lei. Estes podem se encontrar em situação de detidos em prisão preventiva ou que estejam na iminência de ser detidos. Dentre vários princípios, destaca-se os seguintes:

- A não discriminação da criança em relação a raça, cor, sexo, língua, religião, opinião política ou outra da criança, de seus pais ou representantes legais, ou da sua origem nacional, étnica ou social, fortuna, incapacidade, nascimento ou de qualquer outra situação (art. $2^{\circ}$, da CDC);

- Interesse superior da criança $\left(\operatorname{artigo~} 3^{\circ}\right)$;

- Direito à vida, à sobrevivência e ao desenvolvimento $\left(\operatorname{artigo} 6^{\circ}\right)$;

- Respeito pelas opiniões da criança (artigo 12\%);

- O dever de a custódia ou a detenção ser usada

30 PEREIRA, Tânia da Silva. A Convenção e o Estatuto: um ideal comum de proteção ao ser humano em vias de desenvolvimento. In: (Coord.). Estatuto da Criança e do Adolescente: Lei 8.069/90: "estudos sócio-jurídicos". Rio de Janeiro: Renovar, 1992 p. 67-115. p. 68.

31 PEREIRA, Tânia da Silva. A Convenção e o Estatuto: um ideal comum de proteção ao ser humano em vias de desenvolvimento. In: __ (Coord.). Estatuto da Criança e do Adolescente: Lei 8.069/90: "estudos sócio-jurídicos". Rio de Janeiro: Renovar, 1992 p. 67-115. p. 68 .

32 VERONESE, Josiane Rose Petry. Humanismo e infância: a superação do paradigma da negação do sujeito. In: MEZZAROBA, Orides (Org.) Humanismo latino e Estado no Brasil. Florianópolis: Fundação Boiteux, 2003. p. 421-452. p. 434.

33 ORGANIZAÇÃO DAS NAÇÕES UNIDAS. A Convenção sobre os Direitos da Criança: adoptada pela Assembleia Geral nas Nações Unidas em 20 de novembro de 1989 e ratificada por Portugal em 21 de setembro de 1990. Disponível em: <https://www.unicef. pt/docs/pdf_publicacoes/convencao_direitos_crianca2004.pdf $>$. Acesso em: 27 set. 2014 como último recurso (art. 37, da CDC);

- A proibição de torturas e outras formas de tratamento cruel, desumano e degradante ou punição - (alínea a, art. 37, da CDC);

- A proibição da detenção irregular e ilegal, incluindo detenção sem acusação formada ou sem suspeita de envolvimento no cometimento de ofensa criminal (alínea b, art. 37, da CDC);

- A proibição de aplicação de penas de morte e de prisão perpétua aos menores de 18 anos de idade ou de impor estas penas devido aos crimes cometidos antes de 18 anos (alínea a, art. 37, da CDC);

- O dever da separação do recinto da detenção ou prisão dos menores de idade com os adultos, em todas as fases do processo (alínea c, art. 37, da CDC);

- O direito a condições humanas de detenção, incluindo a manutenção do contato com os membros da sua família (alínea c, art. 37, da CDC).

Para as crianças e os adolescentes que tenham que depor em casos como testemunhas, vítimas ou perpetradoras de violação, deve se assegurar o respeito pelos seguintes princípios e direitos: direito à privacidade, direito a proteção, apoio psicológico, direito a assistência legal, excepcionalidade, brevidade e respeito à condição peculiar de pessoa em desenvolvimento (art. 40, da CDC). Em suma, a criança tem o direito de ser protegida contra todas as formas de exploração prejudiciais a qualquer aspecto do seu bem-estar (art. 36, da CDC).

Ainda em relação à preocupação pela proteção dos direitos da criança e do adolescente, especificamente, em conflito com a lei, há outros instrumentos internacionais que servem de referência para o atendimento e a aplicação da justiça juvenil. Nas Regras Mínimas das Nações Unidas para Administração da Justiça da Infância e da Juventude, por exemplo, são detalhadas as diretrizes para a instalação de justiças especializadas e as garantias mínimas que devem ser conferidas à criança e ao adolescente acusado de prática infracional.

A Declaração Universal dos Direitos da Criança, a Convenção Americana de Direitos Humanos, as Diretrizes das Nações Unidas para a Prevenção da Delinquência Juvenil, e as Regras Mínimas das Nações Unidas para a Proteção dos Jovens Privados de Liberdade (Regras de Beijing), são outros instrumentos legais estatuídos pela comunidade internacional a favor dos direi- 
tos da criança e do adolescente, envolvidos em atos criminais. O conteúdo dessas normas permeia a legislação moçambicana relativa à problemática em análise.

Decorrente da Convenção Americana de Direitos Humanos (1969) - Pacto de San José da Costa Rica, no artigo 19, de forma pouco descritiva está plasmado que "Toda criança terá direito às medidas de proteção que a sua condição de menor requer, por parte da sua família, da sociedade e do Estado". A Declaração Universal dos Direitos das Crianças de 20 de novembro de 1959 estabeleceu 10 princípios de proteção da criança e do adolescente. Dentre eles podem-se destacar os seguintes:

\begin{abstract}
Princípio I - A criança desfrutará de todos os direitos enunciados nesta Declaração. Estes direitos serão outorgados a todas as crianças, sem qualquer exceção, distinção ou discriminação [...]. Princípio II - Direito à especial proteção para o seu desenvolvimento físico, mental e social e, disporá de oportunidade e serviços, a serem estabelecidos em lei por outros meios [...]. Ao promulgar leis com este fim, a consideração fundamental a que se atenderá será o interesse superior da criança. Princípio X - A criança deve ser protegida contra as práticas que possam fomentar a discriminação racial, religiosa, ou de qualquer outra índole. Deve ser educada dentro de um espírito de compreensão, tolerância, amizade entre os povos, paz e fraternidade universais e com plena consciência de que deve consagrar suas energias e aptidões ao serviço de seus semelhantes. ${ }^{34}$
\end{abstract}

O $8^{\circ}$ Congresso das Nações Unidas sobre a Prevenção do Delito e Tratamento do Delinquente, criado por meio da resolução $n^{\circ}$ 45/112, de 14 de Dezembro de 1990, e as Diretrizes das Nações Unidas para a Prevenção da Delinquência Juvenil - Diretrizes de Riad, estabelecem políticas e medidas progressistas de prevenção da delinquência juvenil, que se traduzem na participação dos adolescentes nos programas de serviços comunitários, de autoajuda e de indenização e assistência nos casos em que aparecem como vítimas. Ainda no $8^{\circ}$ congresso, foram estabelecidas "Regras das Nações Unidas para a Proteção dos Menores Privados de Liberdade" 35 , tidas como princípios basilares para a consideração da prisão da criança e adolescente em conflito com a lei,

34 FUNDO DAS NAÇÕES UNIDAS PARA A INFÂNCIA. Declaração Universal dos Direitos das Crianças. Disponível em: <http:/ / www.mp.go.gov.br/portalweb/hp/8/docs/declaracao_universal_ dos_direitos_da_crianca.pdf $>$. Acesso em: 27 set. 2014.

35 ASSEMBLÉIA GERAL DAS NAÇÕES UNIDAS. Regras das Nações Unidas para a proteção dos menores privados de liberdade. Disponível em: <http://www.rolim.com.br/2002/_pdfs/066.pdf>. Acesso em: 20 set. 2014. em medida excepcional e no menor espaço de tempo. Estabeleceu-se, também, que deveria ser evitada, ao máximo possível, a ação coercitiva às crianças e aos adolescentes.

A finalidade das regras criadas é de "estabelecer normas mínimas aceitas pelas Nações Unidas para a proteção dos jovens privados de liberdade em todas as suas formas, de maneira compatível com os direitos humanos e liberdades fundamentais e, com vista a se opor aos efeitos prejudicais de todo tipo de detenção [...]" Consta nessas regras que "o sistema de justiça de menores deve respeitar os direitos e a segurança dos menores e promover o seu bem-estar físico e mental. A prisão deverá constituir uma medida de último recurso" ${ }^{37}$.

Relativamente à legislação e administração da justiça da infância e da adolescência, o $8^{\circ}$ Congresso das Nações Unidas sobre prevenção do delito e tratamento do delinquente, deliberou as seguintes regras:

50. Os governos deverão promulgar e aplicar leis e procedimentos especiais para fomentar e proteger os direitos e o bem-estar de todos os jovens. 51. Deverá ser promulgada e aplicada uma legislação que proíba a vitimização, os maus-tratos e a exploração das crianças e dos jovens. 52. Nenhuma criança ou jovem deverá ser objeto de medidas severas ou degradantes de correção ou castigo no lar, na escola ou em qualquer outra instituição. 54. Com o objetivo de impedir que se prossiga à estigmatização, à vitimização e à incriminação dos jovens, deverá ser promulgada uma legislação pela qual seja garantido que todo ato que não seja considerado um delito, nem seja punido quando cometido por um adulto, também não deverá ser considerado um delito, nem ser objeto de punição quando for cometido por um jovem. 55. Poderá ser considerada a possibilidade de se estabelecer um escritório de "proteção da infância e da adolescência” (ombudsman) ou um escritório análogo independente que garanta o respeito da condição jurídica, dos direitos e dos interesses dos jovens e, também, a possibilidade de remeter casos aos serviços disponíveis. Do mesmo modo, deverão ser estabelecidos serviços de

36 ASSEMBLÉIA GERAL DAS NAÇÕES UNIDAS. Regras das Nações Unidas para a proteção dos menores privados de liberdade. Disponível em: <http://www.rolim.com.br/2002/_pdfs/066.pdf>. Acesso em: 20 set. 2014.

37 ASSEMBLÉIA GERAL DAS NAÇÕES UNIDAS. Regras das Nações Unidas para a proteção dos menores privados de liberdade. Disponível em: <http://www.rolim.com.br/2002/_pdfs/066.pdf>. Acesso em: 20 set. 2014. 
defesa jurídica da criança. 56. O pessoal, de ambos os sexos, da polícia e de outros órgãos de justiça deverão ser capacitados para atender às necessidades especiais dos jovens; essa equipe deverá estar familiarizada com os programas e as possibilidades de remessa a outros serviços, e devem recorrer a eles sempre que possível, com o objetivo de evitar que os jovens sejam levados ao sistema de justiça penal. 57. Leis deverão ser promulgadas e aplicadas, estritamente, para proteger os jovens do uso indevido das drogas e de seus traficantes ${ }^{38}$.

Diretrizes semelhantes foram estabelecidas pela Carta Africana dos Direitos e Bem-Estar da Criança, ao dispor no artigo 17 de uma "Administração da Justiça Juvenil" e determinando que "Cada criança ou acusados culpados de terem violado o direito penal terão direito a tratamento especial, de forma coerente com a criança o sentido de dignidade e valor e que reforça a criança o respeito pelos direitos humanos e liberdades fundamentais ${ }^{39}$ ".

A Organização de Unidade Africana (OUA), criada a 25 de maio de 1963 em Addis Abeba, Etiópia, substituída pela União Africana (UA) a 9 de julho de 2002, determina também que os Estados-Membros dessa Carta, em especial devem: assegurar que nenhuma criança que esteja detida ou presa ou de outra forma privada da sua liberdade deva ser submetida a tortura, tratamento desumano ou degradante ou punição; assegurar que as crianças sejam separadas dos adultos em seu local de detenção ou prisão; assegurar que cada criança acusada de violar a lei penal deva ser presumida inocente até devidamente reconhecidos culpados; oferecer assistência jurídica e outras, adequadas para a preparação e apresentação de sua defesa; determinar o assunto a criança o mais rapidamente possível, por um tribunal imparcial e se considerado culpado, tem direito a um recurso apresentado por um tribunal superior; e proibição da imprensa e ao público publicar imagens e julgamento da criança.

Moçambique ratificou diversos instrumentos internacionais que estabelecem garantias de proteção dos direitos da criança e do adolescente em conflito com

38 ORGANIZAÇÃO DAS NAÇÕES UNIDAS. Diretrizes das Nações Unidas para Prevenção da Delinquência Juvenil, Diretrizes de Riad. Disponível em: < http://www.dhnet.org.br/direitos/sip/onu/c_a/ lex45.htm>. Acesso em: 20 set. 2014.

39 ORGANIZAÇÃO DE UNIDADE AFRICANA. Carta Africana dos Direitos e Bem-Estar da Criança. Disponível em: <http:/ / www. didinho.org/CartaAfricDirBEC.pdf>. Acesso em: 20 set. 2014. a lei. São eles: Convenção sobre os Direitos da Criança de 1989; Carta Africana dos Direitos e Bem-Estar da Criança de 1990; Protocolo Adicional à Convenção das Nações Unidas contra Criminalidade Organizada Transnacional, relativo à Prevenção e Punição do Tráfico de Pessoas, em especial Mulheres e Crianças de 2000, ratificados em 1989, 1980 e 2001, respectivamente. Também ratificou as seguintes legislações internacionais: a Declaração Universal dos Direitos do Homem; o Pacto Internacional Sobre Direitos Civis e Políticos; a Carta Africana dos Direitos do Homem e dos Povos; e a Carta dos Direitos Fundamentais, outorgada pela SADC. Essa ação simboliza o compromisso do Governo de Moçambique para com a harmonização da legislação nacional com as normas internacionais.

No entanto, como pode se perceber, há muitos instrumentos internacionais que estabelecem, de uma forma clara, princípios de proteção à criança e ao adolescente em conflito com a lei, tanto a nível internacional, assim como em Moçambique. Contudo, esses instrumentos continuam sendo violados pelas entidades responsáveis pela justiça infantil ou dos que velam sobre a matéria do direito da criança. Por exemplo, no Relatório da Amnistia Internacional de 2012 consta que "durante a sua visita a centros de detenção, encontraram vários jovens que afirmaram e aparentavam ser menores de 16 anos de idade. Alguns, [...], declararam que na altura da sua detenção tinham menos de 16 anos de idade" ${ }^{\prime 40}$.

Em setembro de 2013, “o Diretor Nacional Adjunto dos Serviços Prisionais comunicou que havia 15.663 presos, incluindo 618 prisioneiras e 5.108 menores na faixa etária dos 16 aos 18 anos de idade em prisões projetadas para alojar apenas 7.804"41. Esse cenário revela que as crianças são vulneráveis á violação dos seus direitos humanos básicos. Essas crianças não têm sido colocadas em penitenciárias específicas, ou seja, separadas com os adultos. Estas e outras práticas violam o artigo 37 da CDC, ao dispor que "Nenhuma criança deve ser

40 AMNISTIA INTERNACIONAL. Aprisionando os meus direitos prisão e detenção arbitrária e tratamento dos reclusos em Moçambique. Maputo: Amnesty International, nov. de 2012. Disponível em: $<$ http://www.amnistia-internacional.pt/files/Noticias_anexos/ novembro2012/Mocambique_Aprisionando_os_meus_direitos_ embargado_01h00_de_dia_22nov2012.pdf>. Acesso em: 01 fev. 2016. Índice: AFR 41/001/2012. p. 34.

41 RELATÓRIO dos direitos humanos: Moçambique de 2013. Disponível em: <http://photos.state.gov/libraries/mozambique/19452/pdfs/mozambiquehrrfinal.pdf>. Acesso em: 27 maio 2014. 
submetida à tortura, a penas ou tratamentos cruéis, à prisão ou detenção ilegal [...]. A criança privada de liberdade deve ser separada dos adultos, [...]”.

Todavia, o governo moçambicano mostra-se preocupado com a situação que as crianças e adolescentes em conflito com a lei estão sendo expostas, ou seja, denotam-se ações que evidenciam o compromisso no melhoramento da situação. Por exemplo, ao nível legislativo e em respeito pelas Convenções Internacionais ratificadas no País, o governo estatuiu o conjunto de disposições relativas à proteção jurídica e social à criança e adolescente suspeitos de prática do crime. São eles:

a. A Lei n. ${ }^{\circ} 8 / 2008$, de 15 de julho, que aprova "A organização Tutelar de Menores". Está Lei estabelece o regime jurisdicional aplicáveis à criança que comete um ato tipificado como crime;

b. A Lei no 7/2008, de 9 de julho, Lei de Bases de Promoção dos Direitos da Criança em Moçambique;

c. A Lei no 29/2009, de 29 de setembro, Lei da Violência Doméstica de 2009, que não só tem por objetivo de reforçar a proteção das mulheres, como também de crianças contra o abuso e a exploração sexual em casa e nas comunidades;

d. Lei $n^{\circ} 23 / 2007$, de 1 de agosto, Lei do Trabalho que pró́be especificamente as piores formas de trabalho infantil para as crianças menores de 18 anos, independentemente do local que o menor se encontre (penitenciaria ou casa);

e. Lei $\mathrm{n}^{\circ}$ 10/2004, de 25 de agosto, Lei da Família, que dispõe novas normas jurídicas para responsabilidades parentais, guarda, adoção e herança;

f. Decreto $n^{\circ} 5 / 89$, de 10 de abril, que dispõe sobre a tramitação processual relativa à concessão da adoção e tutela de menores; e;

g. Lei n. ${ }^{\circ}$ 4/2007 de 7, Lei de Proteção Social, que estabelece a necessidade e a exigência da provisão de segurança social básica a pessoas pobres e crianças em situações difíceis.

O dever de observância estrita dos princípios internacionais e nacionais de proteção da criança e do adolescente em conflito com a lei em Moçambique re- cai, não só às entidades públicas (Ministério da Justiça, Conselho Nacional da Criança, Ministério da Mulher e da Ação Social, Ministério do Interior, Tribunal de Menores, Serviço Nacional das Prisões), como também ás organizações não governamentais (UNICEF, UNICRI, SAVE THE CHILDREN etc), por meio de sistemas e serviços legislativos, sociais e administrativos apropriados de apoio e assistência social, com finalidade de diminuir os riscos de violação dos direitos da criança e do adolescente.

\section{JUSTIÇA INFANTIL E A PROTEÇÃO DE CRIANÇAS em Moçambique}

A Lei n. ${ }^{\circ}$ 8/2008, de 15 de julho, que aprova "A organização Tutelar de Menores" e a Lei no 7/2008, de 9 de julho, Lei de Bases de Promoção dos Direitos da Criança, constituem, praticamente, o quadro legal da justiça de menores em Moçambique. A aplicação dessas leis é feita em harmonia com os instrumentos internacionais ratificados em Moçambique (Convenção sobre os Direitos da Criança de 1989; Carta Africana dos Direitos e Bem-Estar da Criança; Protocolo Adicional à Convenção das Nações Unidas contra Criminalidade Organizada Transnacional, relativo à Prevenção e Punição do Tráfico de Pessoas, em especial Mulheres e Crianças de 2000; e demais legislações de proteção à criança e ao adolescente).

A aprovação desses instrumentos legais em 2008 simbolizava o nascimento de um sistema de proteção infantil em Moçambique. Não obstante, reconhece-se a existência neles de certas incongruências, pois não está bem claro a competência de algumas instituições neles elencados. Na percepção de Issá:

Os dois instrumentos legais acima mencionados
[encontram-se] em muitos dos seus aspectos,
ultrapassados e reajustados à realidade. Por
outro lado, em muitas vertentes, o Estatuto e seu
Regulamento não [chegam] a ter qualquer aplicação
prática, designadamente, no que dissesse respeito
aos serviços de assistência social, de observação
e aos estabelecimentos de prevenção criminal
previstos no Estatuto e regulamento. Na verdade,
aqueles serviços e instituições nunca chegaram a
funcionar tal como foram concedidos ${ }^{42}$.

42 ISSÀ, Abdul Carimo Mahomed. Lei de base de proteção da criança, lei da organização jurisdicional de menores e lei sobre o tráfico de pessoas. Maputo: Central Impressora e Editora de Maputo, 2008. p. 69. 
É de concordar com Issá, pois naqueles instrumentos legais, por exemplo, não constam de uma forma explícita os mecanismos e procedimentos claros da competência exclusiva da instituição policial. Esse fato faz com que, em algumas vezes, as crianças permaneçam muito tempo sob custódia policial, já que o primeiro contato entre os menores em conflito com a lei e a justiça infantil é quase atribuído à Polícia da República de Moçambique (PRM), por meio do Departamento de Atendimento à Mulher e Criança Vítimas de Violência Doméstica - Setor que atende as queixas relacionadas com a violência praticada contra a mulher e criança, no domínio das relações domésticas e familiares, e de que não resulte à morte. Esse departamento tem um papel preponderante no atendimento, assistência, registro e encaminhamento dos menores em conflito com a lei à justiça de menores, para além de outras ações que a lei confere.

A juíza-presidente do Tribunal de Menores em Moçambique, Manuela de Oliveira, falando em Maputo num encontro de avaliação da implementação do projeto de reabilitação juvenil, que inclui medidas alternativas à detenção de crianças em conflito com a lei, citada pelo Jornal Notícias de Moçambique, no dia 28 de março de 2014, afirmou que "a manutenção de crianças detidas por muitos dias nas esquadras policiais é uma das contrariedades que dificultam a aplicação de penas alternativas à prisão e, consequentemente, a totalidade do processo de regeneração de menores em conflito com a lei" "3. Muito recentemente assistiu-se esse tipo de situação. Foi no dia 08 de novembro de 2014, quando "um grupo de nove crianças, com idades compreendidas entre 14 e 15 anos, foi detido [...] em Maputo, acusado de protagonizar roubos na via pública com recurso a armas brancas"44. De acordo com o Jornal@Verdade, os menores foram encarcerados na $12^{\mathrm{a}}$ Esquadra da Polícia em Maputo, onde aguardam pelo seguimento dos trâmites legais. A Polícia da República de Moçambique (PRM) justificou a prisão dos menores nos seguintes

43 EM conflito com a lei: Ilegalidades dificultam regeneração de crianças. Noticias on-line, Maputo, 28 mar. 2014. Disponível em: $<$ http://www.jornalnoticias.co.mz/index.php/sociedade/13119em-conflito-com-a-lei-ilegalidades-dificultam-regeneracao-de-criancas>. Acesso em: 01 fev. 2016.

44 NOVE crianças detidas por roubo na via pública em Maputo.Jornal@Verdade, Moçambique, 18 nov. 2014. Disponível em: $<$ http://www.verdade.co.mz/newsflash/50307-nove-criancas-detidas-por-roubo-na-via-publica-em-maputo->. Acesso em: 23 out. 2015. termos:

A detenção ocorreu graças a denúncia de populares, por várias vezes foram ameaçados por aqueles menores com recurso a navalhas, facas e outros instrumentos contundentes, para além de terem perdido os seus pertences. "Esperamos que a detenção sirva de lição para estes e outros menores que enveredam pelo mesmo caminho deixem o mundo do crime e voltem a integrar-se nas suas famílias e tornem-se seres humanos decentes e úteis para a sociedade" ${ }^{45}$.

Manuela de Oliveira entende que "No lugar de manter as crianças nas esquadras por muito tempo o ideal, [...], seria o seu encaminhamento imediato ao Tribunal de Menores, entidade legitimada para tratar todos os procedimentos necessários". Continuamente afirma a juíza que "Esta ilegalidade cometida nas esquadras cria embaraços na aplicação das medidas alternativas à prisão por parte de alguns juízes, fato que compromete o processo de reabilitação dos menores" ${ }^{46}$. Manuela de Oliveira afirma ainda que:

[...] a Polícia tem ficado com os menores por muito tempo, acabando por resolver o problema a seu jeito, sem seguir os procedimentos que estão previstos na lei. Por seu turno, o Vice-Ministro da Justiça, Alberto Nkutumula, confirmou que o procedimento policial é inadequado, fato que compromete todo o processo de condução do menor até ao devido tratamento legal. Joaquim Nhampossa, do Ministério do Interior, reconheceu as falhas cometidas pela Polícia, muitas das quais estão, segundo ele, relacionadas com o desconhecimento da matéria por parte dos agentes ${ }^{47}$.

Dessa forma, alguns pesquisadores veem o fenômeno de existência de crianças e adolescentes em conflito com a lei como sendo um problema derivado da má atuação das autoridades governamentais e não governamentais:

45 NOVE crianças detidas por roubo na via pública em Maputo.Jornal@Verdade, Moçambique, 18 nov. 2014. Disponível em: $<$ http://www.verdade.co.mz/newsflash/50307-nove-criancas-detidas-por-roubo-na-via-publica-em-maputo->. Acesso em: 23 out. 2015.

46 NOVE crianças detidas por roubo na via pública em Maputo.Jornal@Verdade, Moçambique, 18 nov. 2014. Disponível em: $<$ http://www.verdade.co.mz/newsflash/50307-nove-criancas-detidas-por-roubo-na-via-publica-em-maputo- $>$. Acesso em: 23 out. 2015.

47 NOVE crianças detidas por roubo na via pública em Maputo.Jornal@Verdade, Moçambique, 18 nov. 2014. Disponível em: $<$ http://www.verdade.co.mz/newsflash/50307-nove-criancas-detidas-por-roubo-na-via-publica-em-maputo->. Acesso em: 23 out. 2015. 
Quanto aos casos de menores em conflito com a lei, a ausência pode ser explicada, por um lado, pela inexistência de instituições adequadas para lidar com aquele tipo de questões em Moçambique. A precariedade da oferta jurídica e judiciária afasta uma parte considerável da procura potencial. Por outro lado, há muitos casos de menores em conflito com a lei que recebem tratamento inadequado por parte das instituições judiciárias, particularmente a polícia, sendo-lhes aplicadas medidas carcerárias ${ }^{48}$.

Em razão disso, atualmente, o sistema de justiça criminal moçambicano, no que toca às crianças e aos adolescentes em conflito com a lei, carece severamente de uma abordagem centrada no respeito pelos direitos da criança, tal como é requerido pelos instrumentos nacionais e internacionais de Direito Público. $\mathrm{O}$ artigo $1^{\circ}$ da Lei n. ${ }^{\circ} 7 / 2008$, de 09 de julho, é claro neste assunto, ao dispor que o objeto daquela Lei é a proteção da criança e visa, essencialmente, promover e proteger os direitos da criança, tal como se encontram definidos na Constituição da República de Moçambique de 2004 (CRM), na Convenção sobre os Direitos da Criança (CDC), na Carta Africana sobre os Direitos e Bem-estar da Criança e nas demais legislações de proteção à criança.

Esse entendimento mostra que Moçambique recebe e aceita as normas do Direito Internacional e que estas devem ser respeitadas. Aliás, a CRM já dispõe, de forma explicita, no n. 2 do art. 17 que "A República de Moçambique aceita, observa e aplica os princípios da Carta da Organização das Nações Unidas e da Carta da União Africana”. Ademais, estabelece no n. ${ }^{\circ} 1$ do art. 18 CRM que "Os tratados e acordos internacionais, validamente aprovados e ratificados, vigoram na ordem jurídica moçambicana após a sua publicação oficial e enquanto vincularem internacionalmente o Estado de Moçambique". Assim, as normas internacionais "têm na ordem jurídica interna o mesmo valor que assumem os atos normativos infraconstitucionais emanados da Assembleia da República e do Governo, consoante a sua respectiva forma de recepção" (n. ${ }^{\circ} 2$, art. 18 da CRM). É importante ressaltar que a Convenção dos Direitos da Criança (CDC) foi ratificada pela Resolução no 19/90 da Assembleia da República de Moçambique de 23 de outubro.

No entanto, essas normas continuam sendo violadas, como se observa nos procedimentos e tratamentos atuais aos menores em conflito com a lei no País.

48 FUMO, Joaquim; JOSÉ, André Cristiano; SAMO, Saturnino. Estudo diagnóstico da justiça de menores. Maputo: CEIDIMA, 2012. p. 44.
Dessa forma, fica violado o n. $^{\circ} 1$ do artigo $3^{\circ}$ da CDC, ao dispor que: "Os Estados-Partes comprometem-se a garantir à criança a proteção e os cuidados necessários ao seu bem-estar, tendo em conta os direitos e deveres dos pais, representantes legais ou outras pessoas que a tenham legalmente a seu cargo [...]".

No estágio atual que o sistema de justiça de menores em Moçambique apresenta, é correto afirmar que há um grande desconhecimento dos procedimentos para o tratamento correto da justiça de menores, como estabelecem as normas internacionais. Este fator resulta no tratamento inadequado da criança e do adolescente por parte das instituições judiciárias. Estas práticas impróprias têm outras consequências na vida da criança ou do adolescente:

Os adolescentes julgados nos tribunais se distinguem significativamente dos outros adolescentes em muitas das escalas de medida da regulação familiar. As famílias dos adolescentes julgados e internados em instituições são mais desfavorecidas no plano estrutural e que os laços entre os pais e o adolescente são fracos assim como a supervisão parental. ${ }^{49}$

O envolvimento da família constitui um ato muito importante para a repressão da conduta delitiva da criança ou do adolescente em conflito com a lei, nos processos decisórios da justiça criminal.

Dado o seu papel central na socialização das crianças e adolescentes, a família tem sido considerada um fator decisivo no desenvolvimento da delinquência juvenil. Assim, não é por acaso que muitas teorias da delinquência juvenil se centram na estrutura familiar, na interação pais-filhos e nos estilos educativos dos pais ${ }^{50}$.

Nesse entendimento, McCord afirma que "A presença dos pais é reforçada pela comunicação que permite ao adolescente conhecer as opiniões e as expectativas parentais. $\mathrm{O}$ adolescente torna-se então consciente das potenciais consequências que a sua conduta ilícita tem nas suas relações com os pais" "51. Contudo, essa visão, as vezes, é ignorada pelas comunidades, pois, há ocasiões

49 MCCORD, Joan. Forjar criminosos na família. In: FONSECA, António Castro. Comportamento anti-social e familia: uma abordagem científica. Coimbra: Almedina, 2002. p. 15-36. p. 57.

50 NAPLAVA, Thomas; OBERWITTLER, Dietrich. Fatores familiares e delinquência juvenil: resultados da investigação sociológica na Alemanha. In: FONSECA, António Castro. Comportamento anti-social e família: uma abordagem científica. Coimbra: Almedina, 2002, p. 157-180. p. 157.

51 MCCORD, Joan. Forjar criminosos na família. In: FONSECA, António Castro. Comportamento anti-social e família: uma abordagem científica. Coimbra: Almedina, 2002. p. 15-36. p. 41. 
em que, a população sai ao público pressionando ou mesmo criticando a polícia por não manter sob custódia policial as crianças e adolescentes autores de infrações criminais. Nessa perspectiva, as crianças são vistas pelos populares como os principais protagonistas do crime e da insegurança pública que criam pânico no seio das comunidades. A conduta da população pode também significar o desconhecimento dos procedimentos legais que a lei moçambicana e do Direito Público oferece para a garantia dos direitos da criança em conflito com a lei, como por exemplo, a Lei n. $7 / 2008$, de 09 de julho, que contempla vários mecanismos sobre a imputabilidade da criança e adolescente em conflitos com a lei.

Nos termos do artigo 82 da Lei n. ${ }^{\circ} 7 / 2008$, de 09 de julho, a imputabilidade criminal da criança deve ser definida na lei criminal. Dessa forma, em Moçambique, a criança com menos de 16 anos não pode ser sujeita a medidas de privação de liberdade, apenas se lhe podendo aplicar as medidas tutelares previstas por lei (art. 83). Também, a criança maior de 16 anos e menor de 18 que cometa crime de pequena gravidade deve aplicar-se, sempre que possível medida alternativa a de prisão (art. 84). Entretanto, não é o que se observa nos tribunais moçambicanos. Pode-se notar, em relação aos dados apresentados na parte introdutória deste artigo, em que do universo de crianças em conflito com a lei, inquiridas pela UNICEF em 2006, pelo menos 25\% tinham menos de 18 anos de idade, e 18\% tinham menos de 16 . O número cresceu em 2013, em que dados divulgados por Mangue (2013) apontavam para cerca de 2300 crianças e adolescentes em conflito com a lei, estavam mantidos em regime de reclusão, vivendo uma situação de vulnerabilidade no País. Estes fatos violam, não só a própria lei nacional, como também as normas internacionais de direitos da criança.

Que se diga de passagem que a lei moçambicana sobre está matéria apresenta muitas lacunas. Dispõe o n. ${ }^{\circ} 1$, do art. 85 da lei n. ${ }^{\circ} 7 / 2008$, de 09 de julho que, "Salvo o disposto na lei, nenhuma criança criminalmente inimputável será privada da sua liberdade senão em flagrante delito ou por ordem escrita e fundamentada da autoridade judiciária competente". Esse dispositivo legal dá a entender que os menores de 16 anos de idade em Moçambique podem ser presos, desde que seja em flagrante delito ou com um mandato judicial. É este artigo que legitima os agentes da autoridade pública em prender menores inimputáveis, violando as normas internacionais. Se a lei fala de inimputabilidade absoluta dos menores de 16 anos (art. 46 do Código Penal), não há razão para estes serem presos. É necessário aplicar-lhes medidas socioeducativas, o que não necessariamente é sinônimo de prisão.

$\mathrm{O}$ art. 28 da Lei 8/2008, de 15 de julho, elenca uma série de medidas socioeducativas que podem ser aplicadas a crianças e adolescentes em conflito com a lei, das quais se destacam as seguintes: repreensão registrada; entrega à responsabilidade dos pais, tutor, família de acolhimento ou pessoas encarregadas pela sua guarda; acolhimento em instituições de proteção; liberdade assistida da criança; assistência médico-psicológica; colocação em família idônea ou em estabelecimento oficial de educação, em regime de semiaberto; colocação, em regime de internamento, em escolas de formação vocacional; e internamento em estabelecimento de recuperação juvenil.

Uma vez que o n. ${ }^{\circ} 1$ do art. 85, da Lei n. ${ }^{\circ}$ 7/2008, de 09 de julho, autoriza, de forma explicita, a prisão de menores, os números subsequentes deste artigo estabelecem alguns procedimentos que devem ser observados no momento da detenção. É o caso de, em situações que a criança seja privada de sua liberdade, dever-se-á separar dos adultos e se respeitar o direito de manter contatos regulares com a sua família (n. ${ }^{\circ}$, art. 85). Nesses termos, o menor privado de liberdade é assegurado pelo Estado pronto acesso a assistência judiciária e garantido tratamento, com humanidade e com o respeito devido à dignidade da pessoa humana, de forma consentânea às necessidades da sua pessoa e idade (n. ${ }^{\circ} 4$, art. 85).

A prisão de qualquer criança e o local onde se encontre detida devem ser comunicados imediatamente à autoridade judiciária competente e à família do menor detido ou à pessoa por ele indicada (art. 86). Nenhuma criança ou adolescente é privada da sua liberdade sem que exista processo instaurado nos termos da lei (art. 90). As crianças que estiverem em prisão preventiva devem beneficiar-se de todos os direitos e garantias previstas nas Regras Mínimas das Nações Unidas para tratamento de menores em conflito com a lei. Nessas regras, destaca-se a necessidade de as crianças ou os adolescentes estarem separados dos adultos.

O outro direito que se assiste aos menores é a vedação da divulgação de atos judiciais, policiais e administrativos que digam respeito à criança a quem seja atribuída autoria de ato delitivo (art. 94, da Lei n. ${ }^{\circ}$ 7/2008, de 09 de julho) assim como nenhuma criança pode ser 
sujeita a tratamento negligente, discriminatório, violento e cruel, nem ser objeto de qualquer forma de exploração ou opressão. Sendo punidos por lei todos os atos que se traduzam em violação dos direitos ora estabelecidos (art. $7^{\circ}$ da Lei n..$^{\circ}$ 7/2008, de 09 de julho).

Independentemente das dificuldades e contradições que ainda marcam o processo de proteção da criança e do adolescente em conflito com a lei em Moçambique, parece inquestionável que o governo moçambicano assumiu tarefas de grandes proporções (criação de um quadro jurídico favorável à realização dos direitos da criança), com vista a inverter o cenário, o que muitas vezes contrasta com a sua capacidade de dar respostas com a efetividade esperada. Os mecanismos já estão criados na lei, nota-se, nesse momento, a falta de políticas e infraestruturas adequadas para a internação de crianças autores de ato infracional. Não menos importante constata-se, também, a fraca formação do pessoal que lida com matérias do gênero, de modo a dotá-los de conhecimentos básicos que os permitam lidar com os menores sem violar as normas internas e internacionais.

\section{Considerações finais}

Das análises e interpretações feitas neste artigo, é correto afirmar que vários são os instrumentos internacionais de proteção às crianças e aos adolescentes em conflito com a lei, ratificados pelo governo de Moçambique. Essas normas, equacionadas com as leis nacionais, são suficientes para a garantia dos direitos dos visados. Mas o problema continua sendo a inobservância destes instrumentos. Como forma de superar esse problema, a tese de uma formação e capacitação jurídica em matéria do direito da criança aos agentes ligados ao setor da justiça de menores, seja a mais correta.

Outrossim, com base em uma análise restrita aos argumentos apresentados, conclui-se que, apesar dos importantes avanços alcançados no campo da legislação e das políticas de proteção social dos direitos da criança em Moçambique, aprovados a nível nacional, ainda são vários os problemas ligados à proteção das crianças e do adolescente em conflito com a lei, no País. As leis nacionais e internacionais continuam sendo violadas, devido aos maus procedimentos dos agentes responsáveis por esta matéria. Por exemplo, a prisão de menores de 16 anos; falta de coordenação entre as entidades responsável (Polícia, Tribunal, Ministério Público, entre outras) em manter os primeiros contatos, fazer diligências e encaminhar os menores ao tribunal ou instituições vocacionadas à proteção das crianças; o tratamento inadequado de menores; a demora em entregar os menores detidos ao tribunal para a decretação de medidas cautelares diversas da prisão; entre outras práticas contrárias a legislações internas e do Direito Internacional, constituem fenômenos sociais que continuam abalando o sistema de proteção das crianças e adolescentes autores de ato infracional, no País.

No entanto, muitos ainda são os desafios que o governo de Moçambique tem para a cabal proteção e respeito pelos direitos e liberdade dos menores vulneráveis a sanções penais. Para o efeito, é importante que se diga que dentro das instituições do Estado comprometidas com a causa da criança e do adolescente, é indispensável a criação de instituições vocacionadas, não só para aplicar os princípios estabelecidos na lei, como também para socializar, reabilitar, ou mesmo melhorar o tratamento das crianças e dos adolescentes em conflito com a lei. Também, não menos importante, a ampliação das instituições ligadas à assistência médico-psicológica e de internamento para a recuperação juvenil; a aplicação de medidas cautelares diversas da prisão, como por exemplo, a libertação sob advertência, entregando a criança aos cuidados de um progenitor, familiar ou tutor, entre outras medidas diversas da prisão.

\section{ReferênCias}

AMNISTIA INTERNACIONAL. Aprisionando os meus direitos prisão e detenção arbitrária e tratamento dos reclusos em Moçambique. Maputo: Amnesty International, nov. de 2012. Disponível em: < http://www.amnistia-internacional.pt/files/Noticias_anexos/novembro2012/ Mocambique_Aprisionando_os_meus_direitos_ embargado_01h00_de_dia_22nov2012.pdf>. Acesso em: 01 fev. 2016.

ARIÈS, Philippe. História social da criança e da família. Tradução de Dora Flaksman. 2. ed. Rio de Janeiro: LTC, 1981.

ASSEMBLÉIA GERAL DAS NAÇÕES UNIDAS. Regras das Nações Unidas para a proteção dos menores privados de liberdade. Disponível em: <http://www.rolim.com. br/2002/_pdfs/066.pdf>. Acesso em: 20 set. 2014. 
ASSEMBLEIA GERAL DAS NAÇÕES UNIDAS. Regras minimas das Nações Unidas para a administração da justiça de menores (Regras de Beijing). 1985. Disponível em: <http://www.gddc.pt/direitos-humanos/textosinternacionais-dh/tidhuniversais/dhaj-NOVO-regrasBeijing.html>. Acesso em: 01 fev. 2016.

BALEIRA, Sérgio (Coord.). Relatório preliminar da pesquisa sobre "A Criança em Conflito com a Lei". Moçambique: [S.n], abr.de 2003. Consultoria com Save The Children Norway.

BITENCOURT, Cezar Roberto. Código Penal comentado. São Paulo: Saraiva, 2002.

BRASIL. Estatuto da Criança e do Adolescente. 7. ed. Brasília: Câmara dos Deputados, 2010.

COUTO, Isabel Luís do. O problema da idade da imputabilidade penal. 2012. 56 f. Tese (Mestrado) - Programa de Pós-Graduação do Centro Regional do Porto, Escola de Direito, Universidade Católica Portuguesa, Porto, 2012.

EISENSTEEIN, Evelyn. Adolescência: definição, conceitos e critérios. Adolescência \& Saúde, Rio de Janeiro, v. 2, n. 2, p. 1-6, jun. 2005.

EM conflito com a lei: Ilegalidades dificultam regeneração de crianças. Noticias on-line, Maputo, 28 mar. 2014. Disponível em: <http://www.jornalnoticias.co.mz/ index.php/sociedade/13119-em-conflito-com-a-lei-ilegalidades-dificultam-regeneracao-de-criancas $>$. Acesso em: 01 fev. 2016.

FROTA, Ana Maria Monte Coelho. Diferenças concepções da infância e adolescência: a importância da historicidade para sua construção. Estudos e Pesquisas em Psicologia, Rio de Janeiro, v. 7, n. 1, p. 147-160, abr. 2007.

FUMO, Joaquim; JOSÉ, André Cristiano; SAMO, Saturnino. Estudo diagnóstico da justiça de menores. Maputo: CEIDIMA, 2012.

FUNDO DAS NAÇÕES UNIDAS PARA A INFÂNCIA. Declaração Universal dos Direitos das Crianças. Disponível em: <http://www.mp.go.gov.br/portalweb/ hp/8/docs/declaracao_universal_dos_direitos_da_ crianca.pdf>. Acesso em: 27 set. 2014.

FUNDO DAS NAÇÕES UNIDAS PARA A INFÂNCIA. Proteção da criança. Moçambique: UNICEF, 2014. Disponível em: <http://www.unicef.org/mozambique/pt/protection.html>. Acesso em: 27 set. 2014.
HABIAGZANG, Luísa Fernanda; CAMINHA, Renato Maiato. Abuso sexual contra crianças e adolescentes: conceituação e intervenção clínica. São Paulo: Casa do Psicólogo, 2004.

ISSÀ, Abdul Carimo Mahomed. Lei de base de proteção da criança, lei da organização jurisdicional de menores e lei sobre o tráfico de pessoas. Maputo: Central Impressora e Editora de Maputo, 2008.

JACOBINA, Olga Maria Pimentel; COSTA, Liana Fortunato. Para não ser bandido: trabalho e adolescentes em conflito com a lei. Cadernos de Psicologia Social do Trabalho, São Paulo, v. 10, n. 2, p. 95-110, 2007.

MANGUE, Reginaldo. Milhares de crianças estão em conflito com a lei no país.Jornal@Verdade, Moçambique, 27 mar. 2014. Disponível em: <http://www.verdade. co.mz/nacional/45093-milhares-de-criancas-estao-emconflito-com-a-lei-no-pais>. Acesso em: 10 set. 2014.

MARQUES, José Frederico. Tratado de direito penal. Campinas: Bookseller, 1997.

MCCORD, Joan. Forjar criminosos na família. In: FONSECA, António Castro. Comportamento anti-social e família: uma abordagem científica. Coimbra: Almedina, 2002. p. 15-36.

MOÇAMBIQUE. Código de Processo Penal. Maputo: Ministério da Justiça, 1993.

MOÇAMBIQUE. Constituição (2004). Constituição da República de Moçambique. Maputo: Imprensa Nacional, 2004.

MOÇAMBIQUE. Lei n. 7, de 09 de julho de 2008. Lei de Promoção e Proteção do Direito da Criança. Coletânea de legislação nacional de protecção da criança. Maputo: Fundação para o Desenvolvimento da Comunidade, 2009.

MOÇAMBIQUE. Lei n. 8, de 15 de junho de 2008. Lei da Organização Tutelar de Menores. Coletânea de legislação nacional de proteçãa da criança. Maputo: Fundação para o Desenvolvimento da Comunidade, 2009.

MOÇAMBIQUE. Resolução n 32, de 21 de setembro de 2006. Boletim da República, maputo, n. 38, $1^{\text {a }}$ Série, set. 2006. Suplemento.

NAPLAVA, Thomas; OBERWITTLER, Dietrich. Fatores familiares e delinquência juvenil: resultados da investigação sociológica na Alemanha. In: FONSECA, 
António Castro. Comportamento anti-social e família. Coimbra: Almedina, 2002. p. 157-180.

NOVE crianças detidas por roubo na via pública em Maputo. Jornal@Verdade, Moçambique, 18 nov. 2014. Disponível em: <http://www.verdade.co.mz/ newsflash/50307-nove-criancas-detidas-por-roubo-navia-publica-em-maputo->. Acesso em: 23 out. 2015.

ORGANIZAÇÃO DA UNIDADE AFRICANA. Carta Africana dos Direitos Humanos e dos Povos, (1981). Disponível em: <http://a5i.org/wp-content/ uploads /2014/03/12-Ap\%C3\%AAndice-3-CaADHP. pdf >. Acesso em: 22 mar. 2012.

ORGANIZAÇÃO DAS NAÇÕES UNIDAS. A Convenção sobre os Direitos da Criança: adoptada pela Assembleia Geral nas Nações Unidas em 20 de novembro de 1989 e ratificada por Portugal em 21 de setembro de 1990. Disponível em: <https://www.unicef.pt/docs/ pdf_publicacoes/convencao_direitos_crianca2004. pdf $>$. Acesso em: 27 set. 2014.

ORGANIZAÇÃO DAS NAÇÕES UNIDAS. Diretriżes das Nações Unidas para Prevenção da Delinquência Juvenil, Diretrizes de Riad. Disponível em: <http://www.dhnet. org.br/direitos/sip/onu/c_a/lex45.htm>. Acesso em: 20 set. 2014.

ORGANIZAÇÃO DAS NAÇÕES UNIDAS. Pacto Internacional dos Direitos Civis e Políticos (1966). Disponível em: <http://www.oas.org/dil/port/1966\%20Pacto $\% 20$ Internacional $\% 20$ sobre $\% 20$ Direitos $\% 20$ Civis $\% 20 \mathrm{e} \% 20$ Pol\%C3\%ADticos.pdf>. Acesso em: 25 jun. 2012.

ORGANIZAÇÃO DAS NAÇÕES UNIDAS. Pacto In- ternacional sobre os Direitos Econômicos, Sociais e Culturais. 1966. Disponível em: <http://www.unfpa.org.br/Arquivos/pacto_internacional.pdf $>$. Acesso em: 25 jun. 2012.

ORGANIZAÇÃO DE UNIDADE AFRICANA. Carta Africana dos Direitos e Bem-Estar da Criança. Disponível em: <http://www.didinho.org/CartaAfricDirBEC. pdf $>$. Acesso em: 20 set. 2014.

PEREIRA, Tânia da Silva. A Convenção e o Estatuto: um ideal comum de proteção ao ser humano em vias de desenvolvimento. In: (Coord.). Estatuto da Criança e do Adolescente: Lei 8.069/90: "estudos sóciojurídicos". Rio de Janeiro: Renovar, 1992. p. 67-115.

PERES, Maria Fernanda Tourinho; NERY FILHO, Antônio. A doença mental no direito penal brasileiro: inimputabilidade, irresponsabilidade, periculosidade e medida de segurança. História, Ciências, Saúde - Manguinhos. Rio de Janeiro, v. 9, n. 2, p. 335-355, maio/ago. 2002.

RELATÓRIO dos direitos humanos: Moçambique de 2013. Disponível em: <http://photos.state.gov/libraries/mozambique/19452/pdfs/mozambiquehrrfinal. pdf>. Acesso em: 27 maio 2014.

TRINDADE, Jorge. Delinquência juvenil: competência transdisciplinar. 3. ed. Porto Alegre: Livraria do Advogado, 2002.

VERONESE, Josiane Rose Petry. Humanismo e infância: a superação do paradigma da negação do sujeito. In: MEZZAROBA, Orides (Org.) Humanismo latino e estado no Brasil. Florianópolis: Fundação Boiteux, 2003. p. 421-452. 
Para publicar na Revista de Direito Internacional, acesse o endereço eletrônico www.rdi.uniceub.br ou www.brazilianjournal.org.

Observe as normas de publicação, para facilitar e agilizar o trabalho de edição. 